\title{
Thoracolumbar intraspinal tumours presenting features of raised intracranial pressure
}

\author{
LEONE RIDSDALE AND IVAN MOSELEY \\ From the National Hospital for Nervous Diseases, Queen Square, London
}

S U M M ARY Five patients are described in whom a benign or malignant thoracolumbar tumour, producing increased level of cerebrospinal fluid protein, was associated with hydrocephalus or papilloedema or both. A review of the clinical and laboratory features in these and 40 published cases underlines the difficulty in explaining the increased intracranial pressure in such patients. Slow absorption of cerebrospinal fluid as a result of the elevated protein levels or recurrent subarachnoid bleeding may play a part. When patients are discovered to have communicating hydrocephalus or a syndrome resembling benign intracranial hypertension, the finding of increased cerebrospinal fluid protein or any symptoms or signs relative to the spine should suggest the possibility of an intraspinal tumour.

It is well known that patients harbouring spinal tumours may present with symptoms and signs of raised intracranial pressure, or that such symptoms may dominate the clinical picture. While this is perhaps understandable in the case of a tumour in the cervical region, the causes of the pressure changes are less clear when the tumour is situated in the lower spine. In many of the reported cases the cerebrospinal fluid protein content has been markedly raised, but this is not invariable. The present report adds five cases to the 40 in the literature, and illustrates the problematic aspects of this syndrome, as regards clinical presentation and pathophysiology.

\section{Case reports}

CaSe 1 (national hospital no. A43495)

A 49 year old housewife complained of headache, depression, memory loss, and gait disturbance which had progressed over a period of six months. She had been incontinent of urine for two months. Examination revealed moderate dementia and a wide-based, shuffling gait. There was bilateral papilloedema, but no other focal signs were present. Plain skull radiographs were normal, as were cranial isotope studies, but a right carotid

Address for reprint requests: Dr I. F. Moseley, Lysholm Radiological Department, The National Hospital, Queen Square, London WC1N 3BG.

Accepted 9 March 1978 angiogram showed ventricular dilatation (Fig. 1). The patient's headache and drowsiness increased, and a ventricular drain was inserted. The ventricular pressure was raised and the protein content of the fluid was $2.03 \mathrm{~g} / 1$. Ventriculography demonstrated that the hydrocephalus was of the communicating type, but the air did not pass up over the cerebral convexities. This latter finding was confirmed at subsequent pneumoencephalography, at which time the yellowish lumbar spinal fluid, which clotted, contained $32 \mathrm{~g} / 1$ of protein. As her mental state improved on ventricular drainage, the patient complained of back and right leg pain. Plain radiographs of the spine showed no abnormality, but combined lumbar and cisternal myelography demonstrated a $20 \mathrm{~mm}$ diameter smooth intradural extramedullary mass at the lower border of T12 vertebra. The lower part of the spinal cord was displaced to the left, and there were some dilated vessels above the block. The theca appeared irregular. A neurofibroma was removed from the right $\mathrm{L} 1$ root at laminectomy. Three weeks later, the patient's pain was gone, her mental state was normal, and the papilloedema had resolved.

Comment In this patient, who presented clinically as hydrocephalus with papilloedema, the cerebrospinal fluid protein content above the block was raised, and myelography was suggestive of some arachnoiditis. The pneumographic findings were those of a convexity block hydrocephalus. 


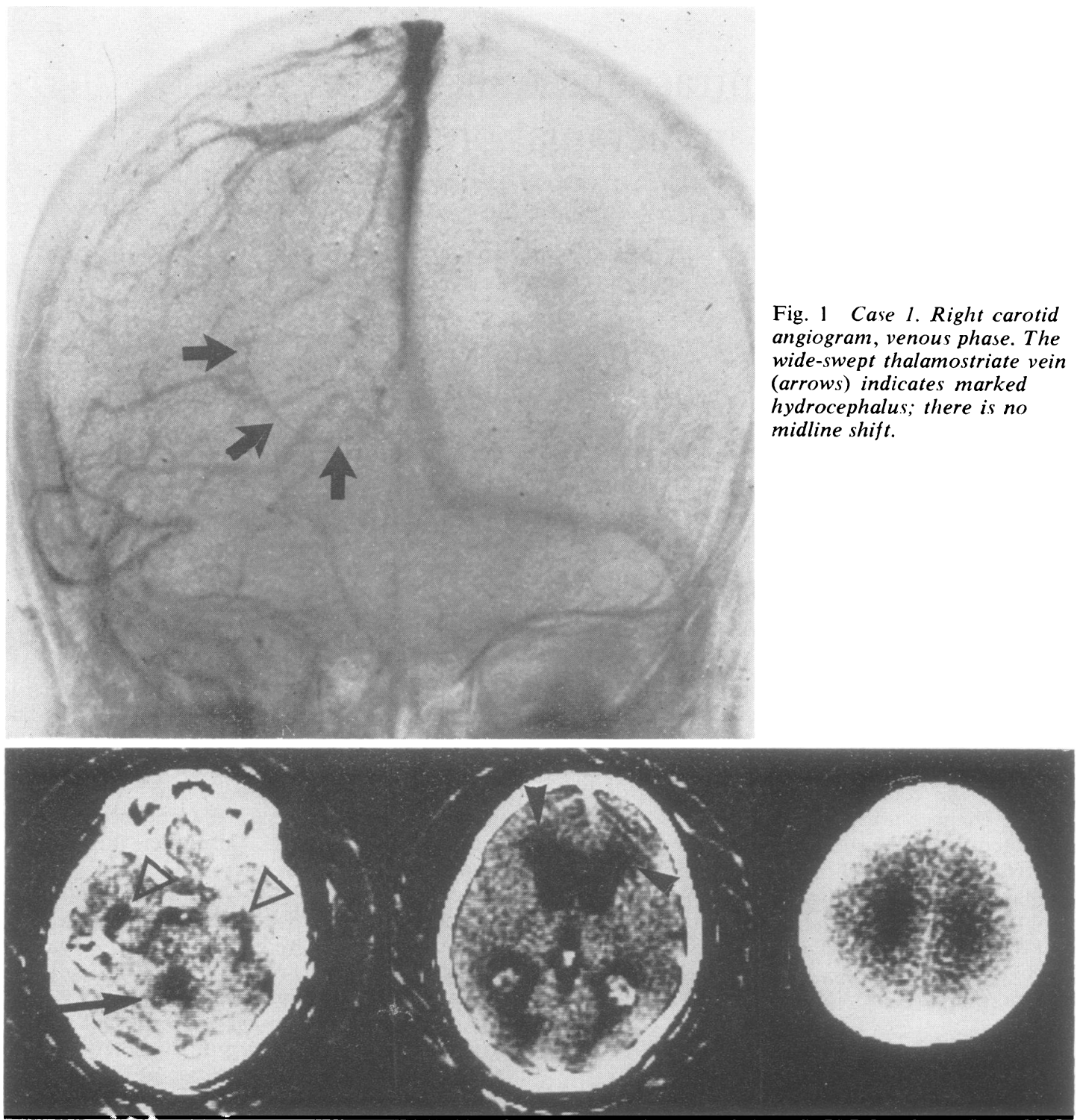

Fig. 2 Case 2. EMI scan. Ventricles, including the fourth (arrow) are dilated. Temporal horns are enlarged (open arrowheads) and there are periventricular lucencies in the white matter around the frontal horns (arrowheads).

CASE 2 (NATional hospital No. A90674)

A 62 year old housewife complained of gait disturbance, with falls, for four months. Her memory had deteriorated, and one week before admission she had become confused and began vomiting. She was drowsy and confused, her neck was stiff, and Kernig's sign was positive on both sides. Fundoscopy showed no abnormality. She could not raise the eyes more than $10^{\circ}$ above the hori- zontal. The tendon reflexes were brisk, and both plantar reflexes were extensor. Lumbar puncture showed xanthochromic fluid, with a protein level of $20 \mathrm{~g} / 1$. Radiographs of the skull showed demineralisation of the dorsum sellae, and computerised tomography (EMI scanning) demonstrated hydrocephalus involving all four ventricles: the basal cisterns were prominent, and there were periventricular white matter lucencies (Fig. 2). A 
ventricular drain was inserted (ventricular fluid protein: $0.99 \mathrm{~g} / \mathrm{l}$ ), and pneumoencephalography was performed. This confirmed the hydrocephalus; the air filled with pontine, interpeduncular, and chiasmatic cisterns, which were also enlarged, but failed to enter the quadrigeminal cistern or cortical sulci. As the patient improved on ventricular drainage, a further history of lumbar pain for three years was obtained. Plain radiography of the spine showed only degenerative changes, but subsequent combined lumbar and cisternal myelography revealed a smooth, intradural, extramedullary mass opposite the second and third lumbar virtebrae, spreading apart the roots of the cauda equina. There was a complete block. A Schwannoma was removed at operation, after which the patient made a complete recovery.

Comment This woman also presented acutely with hydrocephalus, without papilloedema, but with changes on the plain skull radiographs. She had previously complained of back pain, however. Pneumography again showed the picture of communicating hydrocephalus with a convexity block. It is of some interest that both this and the preceding patient had successful pneumography shortly before a myelogram demonstrating a complete block. The CT demonstration of periventricular white matter lucencies in this patient suggested an acute, progressive hydrocephalus. The ventricular protein content was increased.

\section{CaSe 3 (national hospital No. MVH79519)}

A housewife, aged 44 years had complained of pain in the back and both legs for seven years, and it was for investigation of this that she was admitted to hospital. She was then found to have a blood pressure of $170 / 110 \mathrm{mmHg}$, but this fell without treatment to $140 / 90 \mathrm{mmHg}$ within one week in hospital. Fundoscopy showed chronic bilateral papilloedema, with dilated, nonpulsatile veins; there were no hypertensive changes. Visual acuity and fields were normal. There was slight weakness of right hip and knee flexion and of dorsiflexion on both sides, and the left ankle jerk was absent. Skull radiographs and a computerised tomogram (Fig. 3) were normal, as was isotope cisternography (RHISA scanning), but films of the lumbar spine showed evidence of an intraspinal tumour. Iophendylate (Myodil) was injected by cisternal puncture, showing an intramedullary tumour extending from $\mathrm{T} 11$ to $\mathrm{L} 4$ vertebrae where there was a complete block. There was considerable irregularity, suggestive of arachnoiditis. The cerebrospinal fluid protein content was $22 \mathrm{~g} / \mathrm{l}$. At laminectomy, a purplish intramedullary tumour was removed almost completely; there was no evidence of preceding haemorrhage. Histological examination showed a myxopapillary ependymoma without mitotic figures. Fundoscopy six days after operation showed some clearing of the optic discs, and when the patient was seen almost one year after operation this improvement had been maintained.

Comment Here, the presentation was that of a spinal lesion, with papilloedema, without ventricular dilatation, as an incidental finding. Neuroophthalmological examination indicated that the chronic papilloedema was not the result of the mild hypertension, and it began to clear shortly after operation. The cerebrospinal fluid protein level was markedly raised above the lesion.

\section{CASE 4 (NATIONAL hospital No. A58507)}

This man, aged 32 years had been investigated previously in Beirut, where he had presented 18 months earlier, complaining of intermittent headache associated with blurring of vision. The sole abnormality on physical examination was bilateral

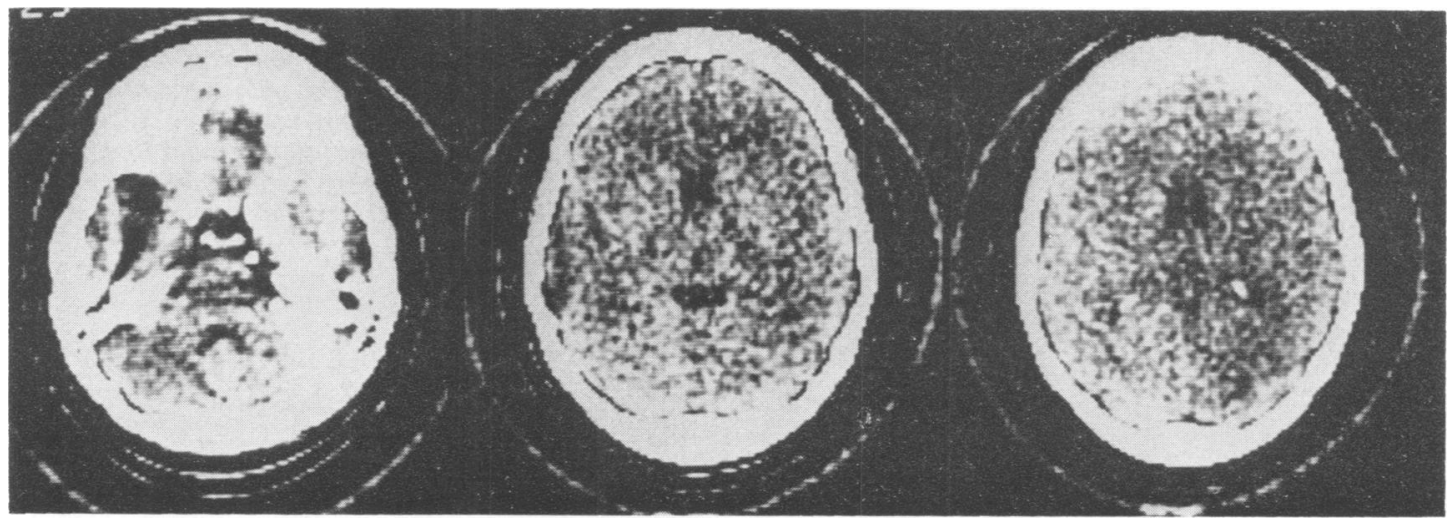

Fig. 3 Case 3. EMI scan. There is no hydrocephalus; ventricles are at the lower limit of normal in size. 
papilloedema. Skull radiographs showed pressure erosion of the lamina dura of the sella turcica (Fig. 4), and there was splaying of the pedicles of T12 and L1 vertebrae. Carotid angiography and positive contrast ventriculography showed communicating hydrocephalus, the oil passing rapidly down to the sacral sac. The ventricular fluid contained $0.38 \mathrm{~g} / 1$ of protein; there were no neoplastic cells. A ventriculoatrial shunt was performed with good results and a pneumoencephalogram at that time was said to be normal, but three months later the patient returned, complaining now of pain in the lower back and right leg. The right leg was weak and the ankle jerk was diminished. There was still marked papilloedema. The illness subsequently progressed, with arm weakness and double incontinence. Myelography was attempted on two occasions, with dry taps between L1 and L3 vertebrae. An upper block was originally shown at L3 intervertebral space, and on the second occasion an irregular mass was revealed at L5 vertebral level. Laminectomy was then carried out in the cervical region as the patient's respiration had deteriorated. It showed extensive haemorrhagic tumour which, on histological examination, turned out to be an oligodendroglioma. The patient died shortly afterwards. Comment The presentation in this case was with raised intracranial pressure, at which time there was no evidence of a cervical lesion. The plain film changes suggested that the tumour first arose at the dorsolumbar junction. The ventricular fluid protein was raised. Ventricular shunting appeared to be effective clinically, without relieving the papilloedema.

\section{CASE 5 (NATional hospital no. A81050)}

A 21 year old Maltese driver was admitted with a history of bifrontal headaches for two months. His family had noted that he was occasionally confused, and he described obscurations of vision and visual hallucinations. He was found to be drowsy but not confused, there was papilloedema on the left, and the right ankle jerk was absent. Plain skull radiographs and gamma camera studies were normal, but computerised tomography showed hydrocephalus affecting the lateral and third ventricles; the fourth ventricle was normal (Fig. 5). Vertebral angiography was also normal. A ventriculoatrial shunt was inserted. The ventricular fluid protein level was $0.48 \mathrm{~g} / \mathrm{l}$. Ventriculography carried out at the same time confirmed the presence of gross communicating hydrocephalus, with no air passing over the cortex. Subsequent lumbar puncture showed xanthochromic fluid with $\frac{\rho}{\square}$ 을 a protein concentration of $9.45 \mathrm{~g} / 1$. Myelography was then undertaken, demonstrating an irregular $\square$ sacral sac, with a markedly irregular mass lying

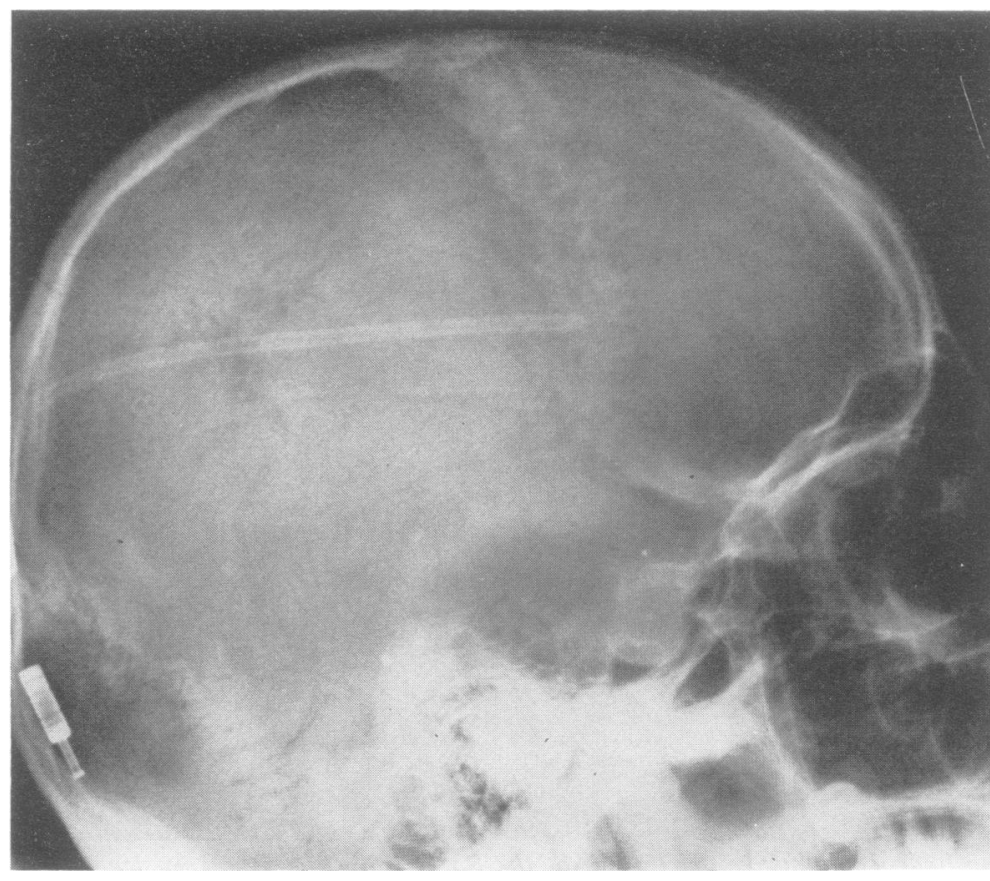

Fig. 4 Case 4. Skull, after ventricular shunting. The lamina dura of the sella turcica is completely eroded, as is the floor of the anterior cranial fossa, indicating longstanding increase in intracranial pressure. 


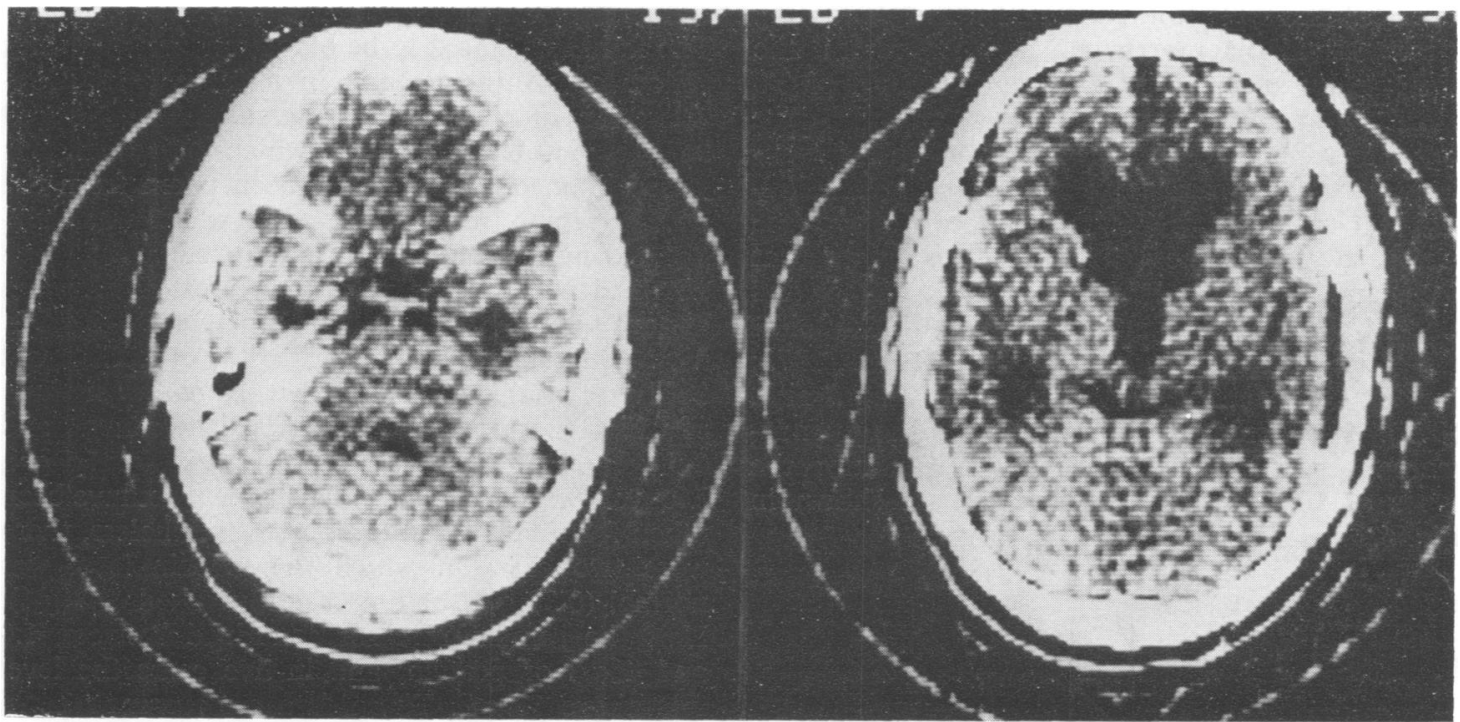

Fig. 5 Case 5. EMI scan. There is marked enlargement of lateral ventricles, including the temporal horns, and the third ventricle. The fourth ventricle is normal.

posterolaterally at the L5 vertebral level. This was thought at surgery to be a soft, benign tumour arising from the $\mathrm{S} 1$ root, but proved to be a malignant tumour of neural origin, possibly an oligodendroglioma or medulloblastoma. As the patient deteriorated after the operation, developing bulbar signs, he was treated with steroids and irradiation of the entire neuraxis, but he died some months later.

Comment Again, the initial presentation was with raised intracranial pressure, but examination did show the absent ankle jerk. The ventricular fluid protein was raised.

All five cases are summarised in the Table.

\section{Discussion}

In the early years of this century there were several reports of fundoscopic changes associated with spinal lesions. Taylor and Collier (1901) reviewed the spinal cases seen at the National Hospital between 1893 and 1899 and described 12 in which "optic neuritis" was found with "myelitis", spinal syphilis, or trauma, or in one case with a "myxoma" at the third cervical level. There were 19 cases with "papillitis or postneuritic atrophy" among 240 cases of local disease of the cord, all having lesions at T2 cord segment or above, except for one case with spinal caries at $\mathrm{T} 5$ vertebra.

The first thoracolumbar lesion presenting with raised intracranial pressure was described in 1931 by Kyrieleis. The patient's predominant symptom was headache. There was papilloedema, and removal of a tumour of unspecified type from the lower thoracic region (T11/12 cord segments) brought about a cure.

There has been a number of subsequent reports of spinal tumours producing papilloedema or hydrocephalus or both. Those which have been analysed for the present discussion include only patients in whom these changes were present before any spinal exploration (since otherwise the role of any postoperative arachnoiditis cannot be

Table Clinical features

\begin{tabular}{|c|c|c|c|c|c|c|c|}
\hline Case & $\begin{array}{l}\text { Age } \\
(y r)\end{array}$ & Tumour type & $\begin{array}{l}\text { Spinal } \\
\text { vertebral } \\
\text { level }\end{array}$ & Presentation & Papilloedema & Hydrocephalus & $\begin{array}{l}\text { CSF site and } \\
\text { protein level } \\
(\mathrm{gl} /)\end{array}$ \\
\hline $\begin{array}{l}1 \\
2 \\
3 \\
4 \\
5\end{array}$ & $\begin{array}{l}49 \\
62 \\
44 \\
32 \\
21\end{array}$ & $\begin{array}{l}\text { Neurofibroma } \\
\text { Schwannoma } \\
\text { Ependymoma } \\
\text { Oligodendroglioma } \\
\text { ? Oligodendroglioma }\end{array}$ & $\begin{array}{l}\text { T12 } \\
\text { L2 } \\
\text { T11 } \\
\text { ?T12 } \\
\text { L5 }\end{array}$ & $\begin{array}{l}\text { Headache, memory loss, gait disturbance } \\
\text { Gait disturbance, memory loss, confusion } \\
\text { Back and leg pain } \\
\text { Headache, visual disturbance } \\
\text { Headaches, confusion, visual disturbance }\end{array}$ & $\begin{array}{l}+ \\
- \\
+ \\
+ \\
+\end{array}$ & $\begin{array}{l}+ \\
+ \\
+ \\
+ \\
+\end{array}$ & $\begin{array}{l}\text { vent: } 2.03 \\
\text { vent: } 0.99 \\
\text { lumb: } 22.00 \\
\text { vent: } 0.38 \\
\text { vent: } 0.48\end{array}$ \\
\hline
\end{tabular}


assessed) and were not associated with fulminating subarachnoid haemorrhage, and in whom the tumour lay at the arbitrarily chosen level of T8 vertebra or below. Very few cases of upper thoracic tumours have been reported in this context. Forty such cases have been described, including that of Kyrieleis (1931) mentioned above (see review by Dardenne (1967) of cases up to that date, and Arseni and Maretsis, 1967; Nasser and Correll, 1968; Nicola and Nizzoli, 1969; Mittal et al., 1970; Gibberd et al., 1972; Neil-Dwyer, 1973; Luzecky et al., 1974; Ammerman and Smith, 1975). The tumours included 24 of the ependymoma series, and 11 were extramedullary; the types of tumours and their levels are shown in Fig. 6.

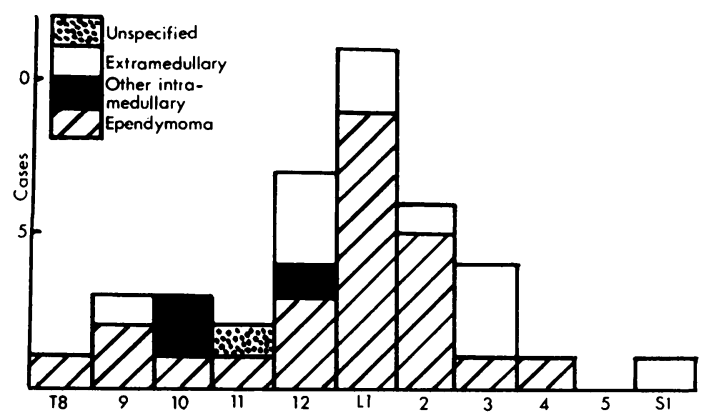

Fig. 6 Type and location of previously reported cases of tumours associated with signs of raised intracranial pressure. The spinal level shown is that of the upper pole of the tumour.

CliniCAL PRESENTATION

About half of the patients gave a history of previous spinal or lower limb problems, but in most cases it was the symptoms of raised intracranial pressure which gave rise to hospital admission. However, in most of the larger reported series of intramedullary spinal tumours (as three-quarters of these lesions were) the proportion of patients who complained of pain as the first symptom has not been higher than 50-70\% (Slooff et al., 1964). The details are not clear in a number of the reports, but it would appear that only about a quarter of the patients presented solely with symptoms of headache, visual disturbance, or dementia, while papilloedema was discovered at the initial neurological examination in about one-eighth. It was suggested in an earlier report (Arseni and Maretsis, 1967) that there was a considerable female predominance, but combining the present cases with those in the literature, figures of 24 females and 21 males are obtained. This does, however, contrast with a $50 \%$ greater incidence of intramedullary tumours in males (Slooff et al., 1964).
CEREBROSPINAL FLUID EXAMINATION

The fluid was stated to be bloody in five cases and yellow or xanthochromic in a further 17. Consideration of the protein content is complicated by the variable site from which the specimens were obtained, some having been taken from the lumbar region below the tumour which was causing a complete block. Thus, ventricular fluid was obtained in 10 of the published cases, all showing abnormally high protein levels: between $1-2 \mathrm{~g} / 1$ in four cases and as much as $5 \mathrm{~g} / 1$ in one. Cisternal fluid was analysed in a further 10 cases, in three of which the protein content was between 0.3 and $0.5 \mathrm{~g} / 1$; in the remainder it was in excess of $1 \mathrm{~g} / 1$. Most of the lumbar specimens appear to have been taken from below the tumour. Nevertheless, there were two cases in which the protein level was normal $(0.38 \mathrm{~g} / 1)$ or only slightly raised $(0.8 \mathrm{~g} / 1)$. Half the remaining cases contained between 1.0 and $4 \mathrm{~g} / 1$ of protein, and in five cases the level was above $10 \mathrm{~g} / 1$. These data are summarised in Fig. 7. There was no obvious correlation between tumour type and protein level. The protein was generally said to be largely albumin, but one ependymoma was associated with an IgG concentration in the CSF of $0.405 \mathrm{~g}$ out of a total of $1.8 \mathrm{~g} / 1$.

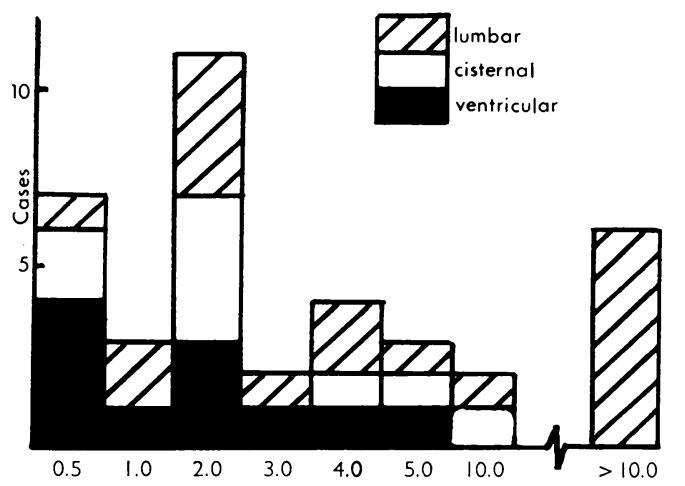

Fig. 7 Cerebrospinal fluid protein levels in published cases (including those in the present report). Lumbar fluid figures are given only when ventricular or cisternal fluid was not analysed. Note that horizontal axis is not linear.

RADIOLOGICAL INVESTIGATION

The skull radiograph was mentioned in 11 cases: it was normal in three, and showed nonspecific manifestations of raised intracranial pressure in the rest. Pneumography was carried out in 29 cases and was normal in seven, although one of these patients had evidence of raised intracranial pressure on the skull films. There were thus 22 patients in whom the ventricles were shown to be dilated, 
although the degree of enlargement was said to be no more than slight in seven. In a number of cases the severity of the hydrocephalus was unstated. Two authors commented on lack of filling of the cerebral sulci with air; another patient had an isotope cisternogram demonstrating abnormal ventricular reflux.

\section{TREATMENT}

Operation on the tumour was successful in relieving the raised intracranial pressure in the large majority (26) of the published cases, but five patients, all with malignant tumours, died postoperatively and five went on to develop optic atrophy. There was evidence of arachnoiditis at operation in a number of cases; two of these were treated by third ventriculostomy, one with success, the other not.

\section{PATHOPHYSIOLOGY}

It is thus clear from a consideration of the 40 cases in the literature and the five described here that a number of problems arise in attempting to explain the development of hydrocephalus or papilloedema or both in these cases. It has been suggested that cervical or upper thoracic intraspinal lesions could actively interfere with cerebrospinal fluid dynamics by their mass effect, especially by preventing the expansion of the spinal subarachnoid space which may play some part in compensating for intracranial pressure/ volume changes (Martins et al., 1972; Pasztor et al., 1975). Since many of these lesions have been confined to the lower lumbar or sacral regions, such an explanation will not suffice.

Elevation of the cerebrospinal fluid protein levels is a striking feature, and it is tempting to incriminate interference with the absorption of fluid at the arachnoid villi as the cause of the intracranial changes. This argument is strengthened by the occasional observation of papilloedema in other conditions giving increased protein concentrations. Thus, Morley and Reynolds (1966) described four cases of the GuillainBarré syndrome with papilloedema from the National Hospital, and reviewed 27 similar cases from the world literature. The protein levels exceeded $4 \mathrm{~g} / 1$ in 18 cases, and were below $2 \mathrm{~g} / 1$ in only five; the spinal fluid pressure had been raised in 19 patients. However, there was no clear correlation between the time course of the increased proteins and the progress of the papilloedema in at least five cases. Moreover, as Joynt (1958) had pointed out, such air studies as had been performed on a small number of patients developing papilloedema with the Guillain-Barré syndrome or with poliomyelitis had shown ventricles of normal size, while brain biopsy indicated the presence of cerebral oedema.

In addition to the patients described in this paper, we have seen bilateral papilloedema in one patient with hypertrophic polyneuritis (cerebrospinal fluid protein $22.9 \mathrm{~g} / \mathrm{l}$ ), three patients with idiopathic spinal arachnoiditis (levels between 5.3 and $28 \mathrm{~g} / \mathrm{l}$ ), two patients with unexplained elevation of the spinal fluid protein concentrations, one of whom showed the picture of communicating hydrocephalus at pneumography, and in three patients after operation for intraspinal tumours, also with increased protein concentrations.

Nevertheless, the cerebrospinal fluid protein level of most published cases of spinal tumours with raised intracranial pressure has been below the mean figure of $9.35 \mathrm{~g} / 1$ given for intramedullary tumours by Slooff et al. (1964): only nine of 301 patients in their series showed papilloedema. In four of these the tumours were in the cervical region, in another the ocular changes occurred only after operation, while in a sixth patient the relationship of operation and optic disc swelling was not clear.

Is haemorrhage from the tumour the important factor? It had occurred in about half the reported cases, but in the remainder no changes were found either in the spinal fluid or at operation to suggest previous bleeding episodes. Although deposition of protein or breakdown products of blood could cause communicating hydrocephalus by interfering with access of the cerebrospinal fluid to the arachnoid villi, other objections arise-notably, for example, the absent or slight ventricular dilatation in more than $30 \%$ of the cases with papilloedema and, indeed, the development of papilloedema in the majority, who might be expected to develop a syndrome more similar to normal pressure hydrocephalus. Papilloedema is an uncommon manifestation of the hydrocephalus after subarachnoid haemorrhage, whereas ventricular dilatation is often marked (Kibler et al., 1961; Shulman et al., 1963). Not more than four from among the published cases or our own series presented clinically as normal pressure hydrocephalus. It is possible that a number of spinal tumours do produce hydrocephalus without consequent papilloedema, and that this complication is relieved by operation on the tumour before becoming clinically apparent. But, if this were the case, more examples of spinal tumour would have been expected among patients presenting with normal pressure hydrocephalus or similar syndromes.

The high proportion of ependymomas among the reported cases probably relates to the pre- 
ponderance in the region of the lower spinal cord and cauda equina of this type of tumour, which may seed throughout the cerebrospinal fluid spaces (although generally in a caudal direction), and tumour cells could block the arachnoid villi. This does not account for the similar picture in patients with benign tumours, nor does it explain the rapid improvement after operation. Our cases 4 and 5 clearly had evidence of more diffuse disease at the time of death, but there was no clinical or radiological evidence of dissemination of the tumour at the time of presentation.

The rapid postoperative improvement is also difficult to explain if the raised intracranial pressure results from blocking of the villi as a result of high protein levels in the cerebrospinal fluid or of chronic repeated haemorrhage in patients without evidence to suggest acute haemorrhagic episodes. In cases of subarachnoid haemorrhage from other causes, prolonged hydrocephalus frequently results from a single bleed. It is conceivable that the spinal operation also acts as an effective decompression of the system. None of the published accounts gives details of the cerebrospinal fluid protein levels after operation, except in cases with recurrent tumour or arachnoiditis.

A further possible explanation is that certain tumours exude not only protein, but considerable quantities of fluid. Any compromise of the mechanisms for absorption could produce elevation of the fluid pressure, causing hydrocephalus or a syndrome resembling benign intracranial hypertension, as in our case 3 . In the latter condition the volume of the cerebrospinal fluid is increased (Johnston, 1973; Martins, 1973); both disturbances could be present in cases of spinal tumour. However, the thoracolumbar meningioma described by Mittal et al. (1970) was extradural and associated with a lumbar fluid protein content of only $0.8 \mathrm{~g} / 1$.

The mechanism of the development of papilloedema in the cases without hydrocephalus remains to be considered. "The entire story of the pathogenesis of papilloedema has not yet been told" (Duke-Elder and Scott, 1971), and although it is generally accepted that pressure on the central retinal vein is the key factor in many cases, such theories as blockage of tissue fluid drainage, forcing of fluids along the nerve sheath, or even direct spread of cerebral oedema along the optic nerve have never been entirely discredited. Their possible role in this situation must be a matter of conjecture.

It is clear that diagnosis of the spinal lesion, which may well be benign, may be delayed while attention is focused on the more striking intracranial problems. This is underlined by the fact that five of the previously reported patients went on to develop optic atrophy, which might possibly have been avoided. We thus advise careful myelography in any patient presenting with a picture of communicating hydrocephalus (particularly with papilloedema) or of probable benign intracranial hypertension in whom there is any indication that a spinal lesion may be present-for example relatively minor increase in the cerebrospinal fluid protein, or appropriate symptoms or signs however slight.

Note added in proof Since this article was submitted for publication, we have seen a 16 year old girl (National Hospital No. A99511) who had been treated for intractable back pain by various conservative methods over the preceding five years. In the five weeks before admission she developed headaches, diplopia, and meningism. She was found to have bilateral papilloedema. Plain radiographs showed increased convolutional markings in the skull and expansion of the spinal canal from the T12 to L3 vertebrae. Cisternal myelography revealed a massive tumour causing a complete block at the L2 level; there was also irregularity in the thoracic region, suggesting arachnoiditis or tumour $\bar{\AA}$ deposits. The spinal fluid protein was in excess of $1 \mathrm{~g} / 1$. An ependymoma was removed at operation. The papilloedema improved, and the EMI scan, which before operation had shown enlargement of the whole ventricular system, now showedo ventricles at the upper limit of normal in size.

\section{References}

Ammerman, B. G., and Smith, D. R. (1975). Papilledema and spinal cord tumours. Surgical Neurology, 2, 555-557.

Arseni, C., and Maretsis, M. (1967). Tumors of the lower spinal cord associated with increased intracranial pressure and papilledema. Journal of Neurosurgery, 27, 105-110.

Dardenne, G. (1967). Hypertension intracranienne et contaminations chimiques et cytologiques du liquide céphalo-rachidien. Acta Neurochirurgica, 17, 46-70.

Duke-Elder, S., and Scott, G. I. (1971). System of Ophthalmology. Vol. 12: Neuro-Ophthalmology, pp. 50-53. Kimpton: London.

Gibberd, F. B., Ngan, H., and Swann, G. F. (1972). Hydrocephalus, subarachnoid haemorrhage and ependymomas of the cauda equina. Clinical Radiology, 23, 422-426.

Johnston, I. H. (1973). Reduced CSF absorption syndrome. Reappraisal of benign intracranial hypertension and related conditions. Lancet, 2, 418-421.

Joynt, R. G. (1958). Mechanism of production of papilledema in the Guillain-Barré syndrome. Neurology (Minneapolis), 8, 8-12. 
Kibler, R. F., Couch, R. S. C., and Compton, M. R. (1961). Hydrocephalus in the adult following spontaneous subarachnoid haemorrhage. Brain, 84, $45-61$.

Kyrieleis, W. (1931). Die Augenveränderungen bei den entzundlichen Erkrankungen des Zentralnervensystems. In Kurzes Handbuch der Opthalmologie, Vol. 6, p. 669. Edited by F. Schieck and A. Bruckner. Springer-Verlag: Berlin.

Luzecky, M. H., Siegel, B. A., Coxe, W. S., and Berg, L. (1974). Papilledema and communicating hydrocephalus. Association with a lumbar neurofibroma. Archives of Neurology (Chicago), 30, 487489.

Martins, A. N. (1973). Resistance to drainage of cerebrospinal fluid: clinical measurement and significance. Journal of Neurology, Neurosurgery, and Psychiatry, 36, 313-318.

Martins, A. N., Wiley, J. K., and Myers, P. W. (1972). Dynamics of the cerebrospinal fluid and the dura mater. Journal of Neurology, Neurosurgery, and Psychiatry, 35, 468-473.

Mittal, M. H., Gupta, N. C., and Sharma, M. L. (1970). Spinal epidural meningioma associated with increased intracranial pressure. Neurology (Minneapolis), 20, 818-820.

Morley, J. B., and Reynolds, E. H. (1966). Papilloedema and the Landry-Guillain-Barré syndrome. Brain, 89, 205-222.
Nasser, S. I., and Correll, J. W. (1968). Subarachnoid haemorrhage due to spinal cord tumors. Neurology (Minneapolis), 18, 87-94.

Neil-Dwyer, G. (1973). Tentorial block of cerebrospinal fluid associated with a lumbar neurofibroma. Journal of Neurosurgery, 38, 767-770.

Nicola, G. C., and Nizzoli, V. (1969). Increased intracranial pressure and papilloedema associated with spinal tumors. Neurochirurgia, 12, 138-144.

Pasztor, E., Pasztor, A., Bodo, M., and Bogsch, S. (1975). The role of spinal subarachnoid spaces in compensation of intracranial hypertension. In Intracranial Pressure 1I, pp. 82-85. Edited by $\mathrm{N}$. Lundberg, U. Ponten, and M. Brock. SpringerVerlag: Berlin.

Shulman, K., Martin, B. F., Popoff, N., and Ransohoff, J. (1963). Recognition and treatment of hydrocephalus following spontaneous subarachnoid hemorrhage. Journal of Neurosurgery, 20, 10401049.

Slooff, J. L., Kernohan, J. W., and MacCarty, C. (1964). Primary Intramedullary Tumors of the Spinal Cord and Filum Terminale. W. B. Saunders: Philadelphia.

Taylor, J., and Collier, J. (1901). The occurrence of optic neuritis in lesions of the spinal cord. Injury, tumour, myelitis. (An account of twelve cases and one autopsy.) Brain, 24, 532-553. 